\title{
DEFINIÇÃO DE ÁREAS PRIORITÁRIAS AO USO PÚBLICO NO PARQUE ESTADUAL DA CACHOEIRA DA FUMAÇA - ES, UTILIZANDO GEOPROCESSAMENTO'
}

Fabricia Benda de Oliveira ${ }^{2}$, Carlos Henrique Rodrigues de Oliveira ${ }^{3}$, Julião Soares de Souza Lima ${ }^{4}$ Maiara Rodrigues Miranda ${ }^{5}$, Reinaldo Baldotto Ribeiro Filho ${ }^{6}$, Erica Rodrigues Munaro Gabrig Turbay ${ }^{7}$ e Fillipe Ferraz $^{8}$

\begin{abstract}
RESUMO - O Parque Estadual da Cachoeira da Fumaça (PECF) está localizado entre os municípios de Alegre e Ibitirama, no sul do Estado do Espírito Santo, possuindo área aproximada de 162,50 hectares. Levando-se em consideração a importância ambiental do PECF para o Estado do Espírito Santo, a necessidade de proteção dos ecossistemas da Mata Atlântica e suas formações associadas, bem como o aprimoramento das técnicas de gestão, este trabalho teve por objetivo propor subsídios aos gestores, através da geração de um mapa de adequabilidade com áreas prioritárias ao uso público, utilizando análise multicritério e lógica fuzzy. Os materiais utilizados foram: Ortofoto do ES, mapa de curvas de nível obtido do Geobases e para coleta de dados em campo utilizou-se GPS diferencial. Os fatores relevantes para avaliação dos aspectos relacionados ao ecoturismo que foram utilizados para produzir os mapas de adequabilidade, seguindo uma ordem de prioridade estabelecida pelo método Analytic Hierarchy Process (AHP) foram: fator cachoeira, uso dos solos, massa de água (contendo os rios), trilhas, locais de acessos, estruturas e declividade. Após a combinação dos fatores, foi gerado o mapa de adequabilidade para uso público, com superfície de adequabilidade mostrando a aptidão e representando o zoneamento da área do PECF para o objetivo proposto. A partir do zoneamento da Unidade de Conservação foi possível mostrar as áreas com diferentes graus de aptidão ao ecoturismo de acordo com suas distâncias da cachoeira, trilhas, e da área de Mata Atlântica.
\end{abstract}

Palavras-chave: Ecoturismo; Zoneamento; Análise multicritério.

\section{DEFINITION OF PRIORITY AREAS FOR PUBLIC USE IN THE CACHOEIRA DA FUMAÇA STATE PARK, ES, USING GEOPROCESSING}

\begin{abstract}
The "Cachoeira da Fumaça" State Park (PECF) is located between the municipalities of AlegreandIbitirama, in the Southern region of thrStateof Espírito Santo, comprising an area of approximately 162.50 hectares. Taking into account the environmental importance of PECF for the State of Espírito Santo, the need to protect the ecosystems of the Atlantic Forest and its associated formations, as well as the improvement of management techniques, this paper proposes subsidies to managers, through the generation of a suitability map with areas destined to public use, using multicriteria analysis and fuzzy logic. The materials used were:Orthophoto of Espírito Santo, contour lines map obtained from Geobases and a differential GPS was used to collect
\end{abstract}

\footnotetext{
${ }^{1}$ Recebido em 29.10.2013 aceito para publicação em 22.09.2014.

${ }^{2}$ Departamento de Geologia, Universidade Federal do Espírito Santo, Centro de Ciências Agrárias, Alegre, ES - Brasil. Email: <fabricia.oliveira@ufes.br>.

${ }^{3}$ Instituto Federal do Espírito Santo, Campus Ibatiba, Ibatiba, ES - Brasil. E-mail: <carlos.oliveira@ifes.edu.br>.

${ }^{4}$ Departamento de Engenharia Rural, Universidade Federal do Espírito Santo, Centro de Ciências Agrárias, Alegre, ES Brasil.E-mail: <juliao.lima@ufes.br>.

${ }^{5}$ Graduada em Engenharia Florestal, Universidade Federal do Espírito Santo, Alegre, ES - Brasil. E-mail: <maiararm123@gmail.com> .

${ }^{6}$ Graduado em Geologia, Universidade Federal do Espírito Santo, Alegre, ES - Brasil. E-mail: <reinaldobrfilho@gmail.com>.

${ }^{7}$ Instituto Estadual de Meio Ambiente e Recursos Hídricos do Estado do Espírito Santo, Alegre, ES - Brasil. E-mail: <emunaro@hotmail.com>.

${ }^{8}$ Graduado em Arquitetura e Urbanismo, Faculdades Integradas de Aracruz, Aracruz, ES - Brasil. E-mail: <fillipe.ferraz7@gmail.com>.
} 
data in the field. The relevant factors for the assessment of aspects related to ecotourism that were used to produce suitability maps, following an order of priority established by the Analytic Hierarchy Process (AHP) method, were: waterfall factor, land use, water body (containing the rivers), trails, access sites, structures and slope. After the combination of factors, a suitability map for public usewas generated, with suitability surface showing the aptitude and representing the zoning of the PECF area for the proposed goal. From the zoning of the Conservation Unit, it was able to show areas with different degrees of aptitude to ecotourism according to their distances from the waterfall, trails, and the Atlantic Forest.

Keywords: Ecotourism; Zoning; Multicriteria analysis.

\section{INTRODUÇÃO}

O Parque Estadual Cachoeira da Fumaça (PECF) é uma Unidade de Conservação (UC) de proteção integral localizada no sul do Estado do Espírito Santo, entre os municípios de Alegre e Ibitirama. O parque teve sua área original de 24 hectares desapropriada em 1984, no entanto só foi legalmente instituído em 2009 no momento da sua ampliação, passando a ocupar uma área de 162,5 hectares (IEMA, 2014). De acordo com Sanches (2012) o principal atrativo turístico do parque, e que levou a sua criação, é a cachoeira da Fumaça, com queda d'água de 144 metros e grande beleza cênica da região que se insere no bioma da Mata Atlântica.

De acordo com Sistema Nacional de unidade de Conservação (BRASIL, 2000), Lei Nº 9.985, as UCs são definidas como meios utilizados com objetivo de garantir a recuperação, conservação e restauração da biodiversidade. Ainda segundo a lei, os parques nacionais, estaduais e municipais são enquadrados na categoria de proteção integral, que são áreas com propósito básico de preservar ecossistemas naturais de relevância ecológica e beleza cênica, e onde pesquisas científicas, turismo ecológico e atividades de educação ambiental são permitidos.

O plano de manejo da UC é um documento oficial que todo parque deve possuir, para direcionar a gestão e deve conter alternativas de utilização do parque, assim como as restrições e limitações ao uso de cada área, e ainda a zona de amortecimento. O PECF possui Plano de Manejo (IDAF, 2001), que está passando por uma atualização devido a mudanças na legislação e na área de amortecimento do parque, e principalmente por não representar a atualidade da UC e o órgão responsável por sua gestão é o Instituto Estadual do Meio Ambiente e Recurso Hídricos do Espírito Santo (IEMA). Assim, o produto deste trabalho tem a pretensão de auxiliar os gestores nessa atualização, bem como nortear as limitações ao uso de cada área.
A delimitação de áreas apropriadas ao uso público em UC é de extrema importância para a administração, visto que auxilia os gestores a adequar o uso dos turistas e a necessidade de conservação de forma a gerar o menor impacto possível sobre os recursos naturais.

Os parques nacionais foram criados de acordo com o Código Florestal em 1934 (decreto 23.793); com a reforma do código em 1965, os parques foram considerados a principal forma de preservação total, mas somente com o Decreto ${ }^{\circ} 84.017$ de 1979 , é que ocorreu a sua regulamentação, definindo também os fundamentos para a instalação e administração dessas áreas (MEDEIROS; PEREIRA, 2011).

Ainda de acordo com os autores os parques representam a categoria mais expressiva entre aquelas de preservação total e a segunda com maior alcance entre todas as unidades de conservação. Mesmo com essa importância, são muito escassas as informações a respeito de um plano de manejo adequado, e sua viabilidade em um método de gestão. A maioria dos parques no Brasil dispõe de plano de manejo, porém nem sempre estão atualizados ou possuem qualidade adequada para orientar uma boa gestão, pois são muito diversos, o que torna difícil apontar um que tenha todas as características requeridas para tal. Alguns contam com excelente informação de base, outros têm uma boa informação cartográfica ou fazem uma discussão de alternativas de solução aos problemas de manejo detectados. Poucos são os planos de manejo que reúnem todas as qualidades requeridas e que tenham estratégias que possam torná-lo executáveis, não cumprindo sua função (DOUROJEANNI, 2005).

O ecoturismo é uma atividade que vem adquirindo cada vez maior popularidade na sociedade, e de acordo com Brasil (2010) prioriza a utilização do patrimônio natural e cultural, de forma sustentável, promovendo o bem estar dos envolvidos. Devido à falta de estudos 
e regulamentação dos planos de manejos das UC, muitas vezes esta atividade ocorre de maneira desordenada, causando assim degradação ao meio ambiente.

Moraes et al. (2008) enfatizam a importância de uma administração estratégica dos empreendimentos que visem o ecoturismo, já que esta é uma das diversas atividades que causam grande impacto no meio ambiente. Essa administração seria contínua e interativa, onde se faria uma verificação do ambiente, a consignação de direções organizacionais, por exemplo.

De acordo com Oliveira et al. (2010) a exclusão das pessoas com o intuito de se proteger uma área cria graves conflitos em todo o mundo, mesmo assim essa é a principal forma de preservação ambiental. Há uma necessidade de se realizar um planejamento das áreas ambientais destinadas ao turismo, já que estas são a matéria-prima para o sustento de muitas comunidades.

Sendo assim, visando o planejamento da UC, este trabalho teve por objetivo definir áreas prioritárias ao uso público no Parque Estadual da Cachoeira da Fumaça - ES, utilizando análise multicritério e lógica fuzzy, através da geração de um mapa de adequabilidade, que poderá ser utilizado pelos gestores para a tomada de decisões, enfocando principalmente as áreas degradadas por atividades antrópicas.

As técnicas que foram utilizadas nesse trabalho diferem das que vem sendo utilizadas por outros autores ou gestores, uma vez que aplica a análise multicritério visando à seleção de áreas mais adequadas ao uso público.

A análise multicritério, vem sendo usada nas mais diversas áreas do conhecimento (CARVALHO et al., 2011; ANTUNES, 2012; CABRAL, 2012; ROQUE, et al., 2013; REZAEI; ORTT, 2013), a fim de definir melhores áreas a um determinado empreendimento. Porém, na definição de áreas prioritárias ao ecoturismo, temos uma lacuna a ser preenchida por essa metodologia, uma vez que não existem trabalhos, principalmente considerando a lógica fuzzy como técnica de normalização dos dados.

\section{MATERIAL E MÉTODOS}

\subsection{Caracterização da área em estudo}

O Parque Estadual da Cachoeira da Fumaça (Figura 1) está localizado nos municípios de Alegre e Ibitirama, na região do Caparaó, sul do Estado do Espírito Santo e está compreendido entre as coordenadas $\mathrm{E}=227500 \mathrm{~m}$ e $229400 \mathrm{~m}$ e $\mathrm{S}=7717700 \mathrm{~m}$ e $7715800 \mathrm{~m}$.

De acordo com a classificação de Köppen (KÖPPEN, 1948) o clima da região é caracterizado como Tropical Chuvoso (Aw), com temperatura média anual abaixo de $15^{\circ} \mathrm{C}$ e precipitação média anual de $1700 \mathrm{~mm}$. O relevo caracteriza-se como montanhoso (IDAF, 2001) e a vegetação é caracterizada como Floresta Estacional Semidecidual, sob domínio da Mata Atlântica (IBGE, 1993).

De acordo com Turbay et al. (2012) a Serra do Caparaó está estruturada como um grande domo, apresentando grande contraste de altitudes, como por exemplo o formador da cachoeira e das escarpas dos morros no entorno. Caracteriza-se pela presença de duas unidades litológicas principais, sendo elas: Biotitagnaisse e granada-biotita-gnaisse.

\subsection{Material}

Para realização deste trabalho foram coletados dados em campo, de trilhas, com marcação de pontos utilizando GPS diferencial. Utilizou-se também ortofotos, compatíveis com a escala 1:15.000, obtidas junto ao

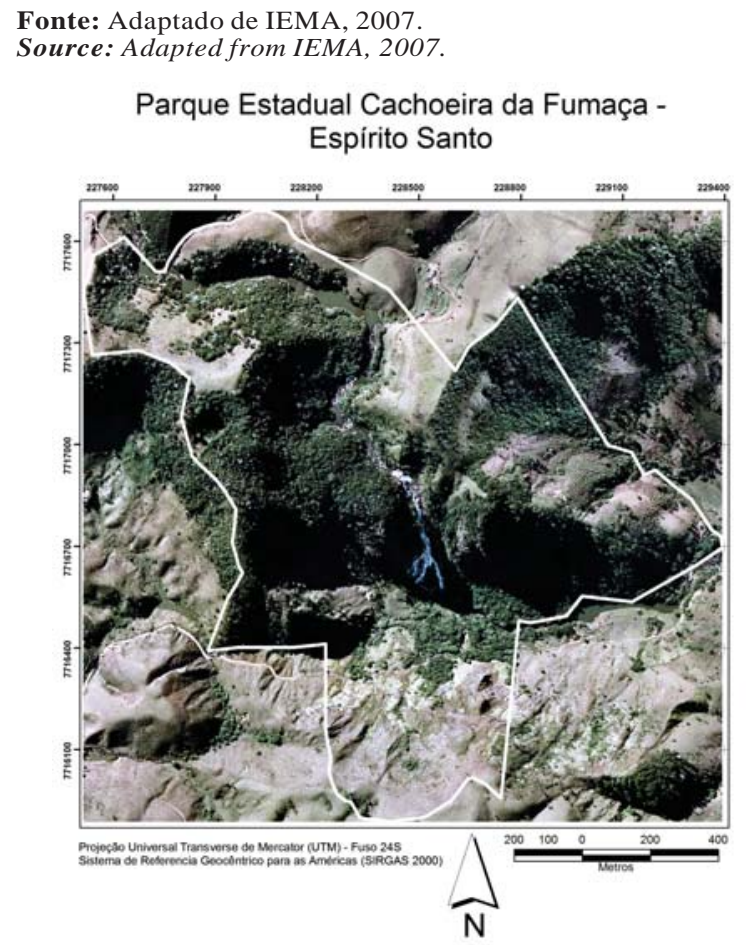

Figura 1 - Ortofoto do Parque Estadual da Cachoeira da Fumaça. Figure 1 - Orthophoto of" Cachoeira da Fumaça" State Park.

Revista Árvore, Viçosa-MG, v.38, n.6, p.1027-1036, 2014 
Instituto Estadual de Meio Ambiente e recursos hídricos (IEMA, 2007), a partir das quais, foram vetorizadas as feições massa d'água e estruturas; o mapa de curvas de nível, foi obtido do Geobases (2002), na escala 1:50.000; e o mapa de uso do solo utilizado possui escala 1:50.000. A fim de compatibilizar a base cartográfica, os mapas foram transformados em raster, em ambiente de SIG, considerando a resolução espacial de 7 metros, o que permite operações de sobreposição entre diferentes camadas de informações.

O mapa de ocupação e uso do solo, ou uso da terra indica toda cobertura vegetal presente no PECF, sendo elas: áreas de pastagem, estádio avançado, intermediário e inicial de sucessão ecológica e macega. Este mapa é essencial para fornecer subsídios para promover a adequação e gerenciamento do uso público aos ambientes.

\subsection{Procedimentos técnicos}

Os procedimentos técnicos adotados no presente trabalho incluíram o levantamento e a análise das condicionantes, por meio da aquisição, armazenamento e descrição dos dados vetoriais e raster, para posterior análise espacial. Foi utilizada a lógica fuzzy para gerar a padronização de todos os mapas de fatores e a análise multicritério para fazer a combinação dos fatores com seus respectivos pesos em um único mapa.

\subsubsection{Critérios escalonados (fatores)}

De acordo com Benda et al. (2012) um fator é um critério que destaca ou diminui a adequabilidade de uma alternativa, definindo o quanto o ambiente ou área está apto ao uso considerado. As alternativas são definidas em termos de uma medida contínua de adequabilidade que varia de 0 a 255, enfatizando ou atenuando a importância de uma alternativa em consideração.

Os fatores (cachoeira, uso dos solos, massa de água contendo os rios, trilhas, locais de acessos, estruturas e declividade) foram normalizados a partir da aplicação de conjuntos fuzzy, dando a todas as localizações um valor que representou o seu grau de adequabilidade.

\subsubsection{Avaliação de pesos para os critérios}

A importância relativa dada a cada critério é uma das dificuldades encontradas para tomada de decisão, visto que cada tomador de decisão julga justo uma ordem de prioridade de acordo com sua visão do ambiente.
De acordo com Calijuri et al. (2002) para estabelecer normas de como um determinado atributo interfere no processo de classificação, é necessário a aplicação do conjunto fuzzy. Essa pertinência se dá por uma transição gradual variando de 0 a 255. Ao contrário da lógica booleana, onde a condição de fazer parte ou não é uma transição abrupta, havendo apenas duas possibilidades definidas, 0 ou 1 . Após a normalização, atribui-se pesos aos critérios, quantificando a importância relativa de cada um deles no processo de decisão e embora não exista um método consensual para a atribuição de pesos, o que será utilizado nesse trabalho é o método baseado na comparação de critérios par-a-par.

A escolha das áreas aptas ao uso público sofre interferência direta dos fatores que contribuem com diferentes valores no processo final de decisão. Dessa forma foi estabelecida a ponderação dos fatores de acordo com sua importância e o peso final de cada fator foi estimado através do método AHP (“Analytical Hierarchy Process” - Processo de Hierarquização Analítica) aplicado à matriz de comparação par-a-par, obtendo-se os pesos para fatores utilizados.

\subsubsection{Normalização dos fatores}

Para normalização dos fatores, foi utilizada a função de pertinência da teoria de conjuntos fuzzy monotônica sigmoidal decrescente (Figura 2), onde 255 representa a adequabilidade máxima e decresce até zero, que representa adequabilidade mínima para o fator avaliado.

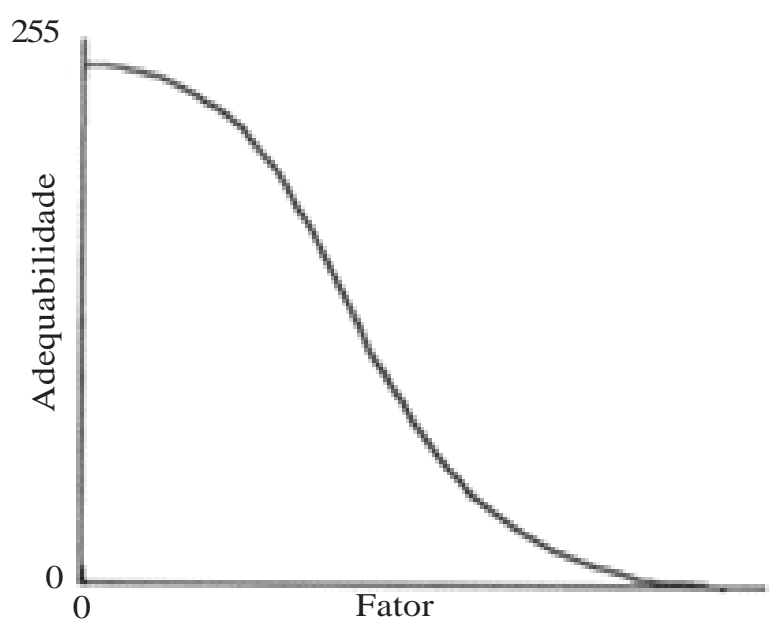

Figura 2 - Função de pertinência sigmoidal monotônica decrescente para padronização dos fatores.

Figure 2 - Function of sigmoidal monotonically decreasing relevance to standardization of factors. 
O fator uso do solo foi reclassificado atribuindo às classes valores de 0 a 255 como pode ser verificado na tabela 1. Essa reclassificação levou em consideração a vulnerabilidade de cada cobertura vegetal e a sua capacidade de regeneração natural devido à utilização da área pelos visitantes, de acordo com a sucessão ecológica, sendo as áreas com maior perturbação as mais vulneráveis.

Considerando a escala utilizada, e sendo o mapa de uso do solo composto por classes, impossibilitando a aplicação direta da função de pertinência fuzzy, fezse a reclassificação deste, considerando classes de adequabilidade variando dentro dessa escala. Os valores de cada classe foram estipulados levando-se em consideração que a pastagem possui maior vulnerabilidade ao uso, seguida pela macega, que apesar de não poder ser considerada formação florestal, possui menor grau de degradação quando comparada a pastagem, possibilitando seu uso. A classe estádio intermediário de sucessão ecológica foi considerada de maior adequabilidade uma vez que o estudo aborda o uso público da área, o que seria impraticável para o estádio avançado de sucessão, por ser esta de formação mais fechada. Além disso, a classe intermediária possui maior número de espécies do grupo das secundárias iniciais e tardias, que aceleram a regeneração natural após a abertura de clareiras ou outras intervenções (MARTINS, 2013). Qualquer intervenção na classe de estádio avançado acarretaria numa regeneração mais lenta quando comparada ao estágio de sucessão ecológica intermediário.

Para os visitantes, quanto mais próximo dos rios e cachoeiras, mais adequado o uso, visto que o ecoturismo busca explorar a beleza cênica oferecida pelo meio ambiente. Entretanto, sabendo-se que a ação antrópica pode interferir na conservação, no que diz respeito às nascentes e minas d’água deve-se respeitar um limite mínimo de 50 metros para a preservação do ambiente, previsto no código florestal brasileiro (BRASIL, 2012).

Tabela 1 - Normalização das classes de uso do solo. Table 1 - Normalization of land use classes.

\begin{tabular}{lc}
\hline Classes de uso do solo & Valor atribuído \\
\hline Estádio avançado de sucessão ecológica & 225 \\
Estádio intermediário de sucessão ecológica & 255 \\
Estádio inicial de sucessão ecológica & 195 \\
Macega & 165 \\
Pastagem & 0 \\
\hline
\end{tabular}

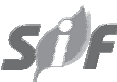

Para normalização do fator declividade foram consideradas áreas impróprias para uso as com declividade acima de 45 graus. É importante delimitar áreas íngremes para racionalizar o uso público para locais apropriados, dessa forma a delimitação das áreas íngremes foi feita a partir do mapa de declividade. As áreas que possuem declividade acima de 45 graus de inclinação, de relevo escarpado, foram consideradas impróprias para uso público, pois dificultam a acessibilidade, assim como geram risco de quedas nas caminhadas dos visitantes. Além disso, segundo o Código Florestal Brasileiro (BRASIL, 2012) áreas em topos de morros ou com inclinação acima dos $45^{\circ}$ devem ser preservadas.

Para normalização do fator massa d’água, as distâncias de 0 a 2 metros foram reclassificadas como de alta adequabilidade (valor 255), considerando que os recursos hídricos são de interesse para o ecoturismo e são áreas ideais e quanto mais longe destes, pior a adequabilidade da área ao uso.

Nas trilhas há alta adequabilidade para o ecoturismo, visto que os locais além de estarem demarcados proporcionam facilidade para caminhar, pois ao demarcar uma trilha procura-se o caminho de mais fácil acesso. À medida que se afasta da trilha original o visitante pode criar mais impactos negativos ao ecossistema, como pisoteamento e compactação do solo, criação de caminhos preferenciais de drenagem, erosão, degradação do ecossistema como um todo, etc. Assim, a adequabilidade foi definida maior quanto mais próxima da trilha, sendo que acima de 30 metros de distância, a adequabilidade torna-se nula (valor 0 ), considerando uma visibilidade média para evitar que os turistas se percam.

O mapa de estruturas, que considerou as estruturas que o parque contém para apoio ao recebimento do turista, sendo elas: banheiros, sala de espera, lanchonete, bebedouro, assentos, etc., foi gerado através de levantamento de dados em campo. Quanto mais próxima a área estiver das estruturas do parque, maior a adequabilidade.

O acesso a uma área de conservação deve ser feito por pontos de acesso já estruturados, para que seja evitado o uso descontrolado da área. Os pontos de acesso possuem geralmente uma estrutura adequada para receber os visitantes, além de possuírem trilhas já demarcadas e sendo utilizadas. Caso os visitantes

Revista Árvore, Viçosa-MG, v.38, n.6, p.1027-1036, 2014 
prefiram conhecer o parque por outros locais, podem comprometer os recursos naturais disponíveis, assim como gerar sérios impactos. Assim, quanto mais longe dos pontos de acesso, menor a adequabilidade da área.

\subsubsection{Combinação dos critérios}

Para a elaboração do mapa final de zoneamento de áreas favoráveis ao ecoturismo, o valor de cada um dos fatores foi combinado através do método de combinação linear ponderada, que é um modelo matemático (equação 1) onde o resultado final (F) será o somatório do valor de todos os fatores (Pij) multiplicados pelos seus respectivos pesos (Xi) (EASTMAN et al., 1995).

\section{$\mathbf{F}=\boldsymbol{\Sigma} \mathbf{P i j} . \mathbf{X i}$}

Os pesos foram adotados levando-se em consideração uma ordem de importância, na qual se atribui diferentes valores relativos a cada um dos fatores no processo de agregação, indicando a importância relativa de todos os fatores e a compensação entre eles. Os pesos são desenvolvidos por uma série de comparação de pares, de importância relativa de cada um dos fatores à adequabilidade dos pixels à atividade que está sendo avaliada.
Levando-se em consideração sua influência sobre a análise, utilizou-se a seguinte ordem de prioridade dos fatores: declividade, estruturas, acesso, trilhas, massa d’água, uso do solo e cachoeira.

\section{RESULTADOS}

Os mapas de fatores (Figura 3) fornecem uma ideia inicial de como será o mapa final, uma vez que estes serão relacionados entre si através da Combinação Linear Ponderada.

O mapa de declividade (Figura 3A) mostra que grandes áreas são aptas ao ecoturismo, visto que possuem baixa declividade (menor que $45^{\circ}$ ). O mapa de estruturas (Figura 3B) mostra que há maior adequabilidade ao ecoturismo no centro do parque, pois correspondem as áreas onde se encontram as estruturas de suporte ao turista. Para os mapas de acesso (Figura 3C) pode-se observar que as áreas de mais alta favorabilidade estão na parte noroeste e oeste do parque e indicam os melhores caminhos para se chegar ao parque. Observando o mapa de trilhas (Figura 3D) verifica-se que há apenas uma pequena faixa de favorabilidade, pois ao afastar-se da trilha aumentam os riscos de se perder além de poder criar mais impactos negativos ao ecossistema. No mapa

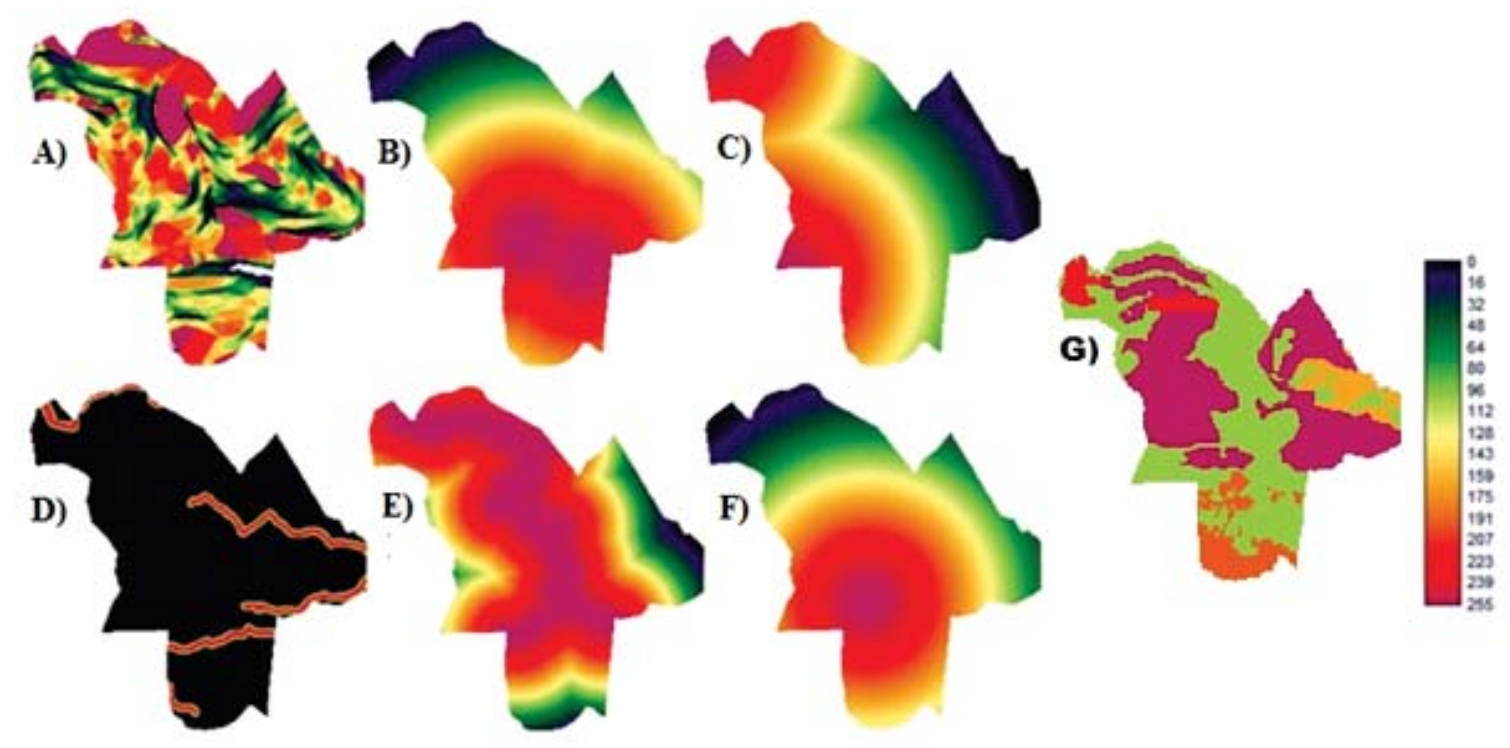

Figura 3 - A) Fator declividade; B) Fator estruturas; C) Fator acesso; D) Fator trilhas; E) Fator massa de água; F) Fator cachoeira; e G) Fator uso do solo.

Figure 3 - A) Slope factor; B) Structures factor; C) Access factor; D) Trails factor; E) Water body factor; F) Waterfall factor; and $G$ ) Land use factor.

Revista Árvore, Viçosa-MG, v.38, n.6, p.1027-1036, 2014 
de massa d’água (Figura 3E) é possível identificar uma grande zona de favorabilidade alta, pois o parque é cortado por esse corpo hídrico e é uma de suas atrações. O fator cachoeira (Figura 3F), que é o principal dos fatores, possui sua maior faixa de adequabilidade no meio do parque, visto que é onde está localizada a Cachoeira da Fumaça. No mapa de uso do solo (Figura 3G), observa-se alta adequabilidade da classe estádio intermediário de sucessão ecológica (valor 255), seguido pelo estádio avançado (valor 225), estádio inicial (valor 195), macega (valor 165) e inaptidão ao uso para a classe pastagem (valor 0 ).

\section{DISCUSSÃO}

O resultado final dos pesos calculados para o fator declividade foi 0,0823 , para o fator estruturas 0,1009 , para o fator acesso 0,1154 , para o fator trilhas 0,1352 , para o fator massa de água 0,1580 , para o fator uso do solo 0,1814, e para o fator cachoeira 0,2268. A proporção de consistência foi zero, indicando que os pesos dos fatores foram aceitáveis na análise.

Após a aplicação da Combinação Linear Ponderada foi gerado o mapa de adequabilidade (Figura 4) que apresenta os valores variando entre 0 e 255, onde áreas com adequabilidade 0 , não possuem potencial para o ecoturismo e as com valor 255 representam os melhores lugares para visitação do parque.

A partir do mapa da figura 4, é possível selecionar áreas com maior potencial ecoturístico, desenvolvendo assim treinamento específico para os guias do parque com o intuito de melhor conduzir os turistas. Além disso, o mapa nos permite verificar outras áreas que podem possuir boa aptidão e direcionar para a visitação dessas áreas, através de novas rotas, trilhas ou passeios sugeridos pelos gestores do parque, a fim de explorar melhor as belezas do parque de forma consciente.

Resultados semelhantes foram encontrados por diversos autores, utilizando análise multicritério combinada com algum método de comparação, como por exemplo: Calijuri et al. (2002), estudando áreas para implantação de aterro sanitário, Zambon et al. (2005), estudando a localização de usinas termoelétricas, Caixeta et al. (2012), mapeando áreas susceptíveis a movimentos de massa e Franco et al. (2013), estudando áreas prioritárias para restauração de Área de Preservação Permanente.

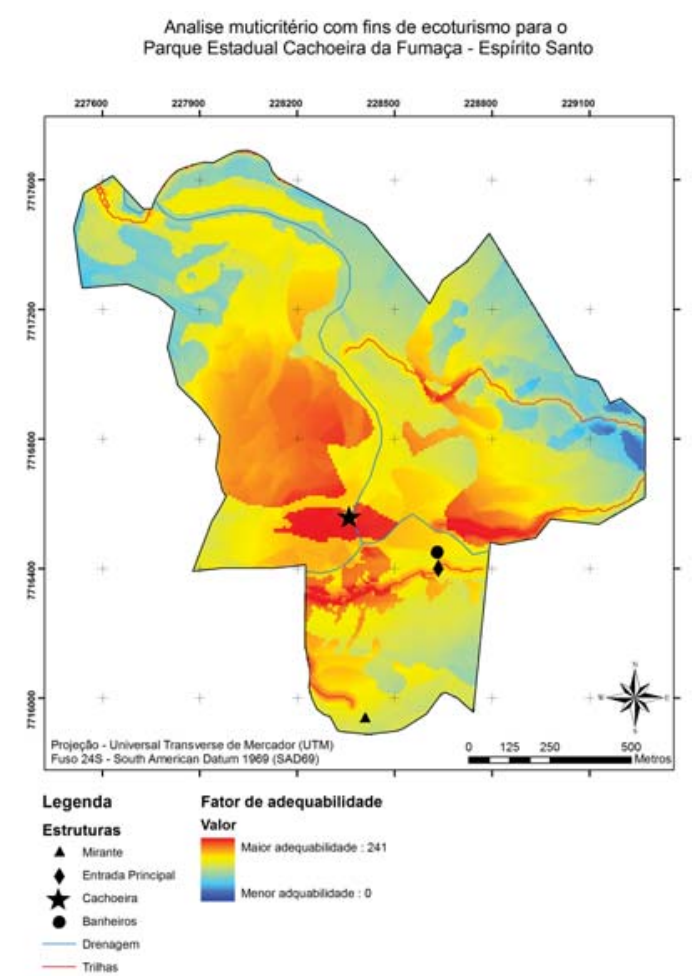

Figura 4 - Mapa final da análise multicritério mostrando as diferentes aptidões ao ecoturismo dentro do Parque Estadual da Cachoeira da Fumaça.

Figure 4- Final map of multicriteria analysis showing different aptitudes to ecotourism within the "Cachoeira da Fumaça” State Park.

Pode-se notar a grande influência do fator cachoeira no mapa final de adequabilidade, já que o mesmo possui o maior peso entre os demais fatores e representa o cartão-postal do parque. Outro fator que influenciou mais no mapa final é o fator uso dos solos, pois considerando que o parque trata-se de área de mata Atlântica, essas áreas foram prioritárias nas análises.

Podemos observar no mapa da figura 4, que podem ser estudadas áreas de acesso e de interesse ao ecoturismo. Para isso, torna-se de fundamental importância definir qual o valor que representa baixa e alta adequabilidade, com intuito de atender os padrões para o ecoturismo na UC.

Após comparação dos dados gerados no mapa da figura 4, e seguindo o que Calijuri et al. (2002) definiram como adequabilidade alta, definiu-se que áreas com adequabilidade acima de 200, seriam as áreas mais indicadas para o ecoturismo. Assim, pode-se

Revista Árvore, Viçosa-MG, v.38, n.6, p.1027-1036, 2014 
definir quatro principais áreas com alta adequabilidade, que estão próximas da cachoeira, das estruturas do parque e de trilhas, ou então estão em áreas de Mata Atlântica.

\section{CONCLUSÃO}

Com o zoneamento da UC foi possível indicar áreas aptas ao ecoturismo, e propor orientação aos gestores para restringir o uso em ambientes não adequados e que estão sendo utilizados atualmente, como por exemplo, em locais próximos a trilhas, porém com baixa adequabilidade. Assim, utilizando o mapa final como guia e observando o potencial turístico do PECF é possível incluir novas atividades de recreação, como passeios em áreas que possuem grande potencial para uso público, mas ainda não são utilizadas.

A aplicação da análise multicritério aliada a uma boa base de dados foi essencial para promover o zoneamento do PECF. O método facilitou a ponderação dos fatores considerados importantes e apresentou resultados satisfatórios na geração de mapas temáticos. A interação e a influência de cada fator no zoneamento podem variar de acordo com os objetivos que venham a ser propostos pelos gestores das UCs e podem contribuir para a produção de diferentes planos de manejo.

\section{AGRADECIMENTOS}

Os autores agradecem à Fundação de Amparo à Pesquisa do Espírito Santo (FAPES), pelo financiamento do trabalho e pelas bolsas concedidas, aos gestores do Parque Estadual Cachoeira da Fumaça (PECF), pela contribuição para o desenvolvimento desta pesquisa e a Universidade Federal do Espírito Santo, por disponibilizar a sua infraestrutura para o processamento dos dados.

\section{REFERÊNCIAS}

ANTUNES, Ó. E. D. Análise multicritério em SIG para determinação de um índice espacializado de pressão antrópica litoral. Casos de Espinho, Caparica e Faro. 2012. 108 f. Dissertação (Mestrado em Gestão do Território com Especialização em Deteç̧ão Remota e Sistemas de Informação Geográfica) - Faculdade de Ciências Sociais e Humanas - Universidade Nova de Lisboa, Lisboa, 2012.
BENDA, F.; ALVES, M. G.; OLIVEIRA, C. H. R. Favorabilidade de áreas para implantação de aterros controlados no município de Campos de Goytacazes/RJ utilizando sistemas de informação geográfica. Revista Brasileira de Cartografia, v.64, n.1, p.33-44, 2012.

BRASIL. Lei no 9.985, de 18 de Julho de 2000. Constituição Federal, Brasília, DF. Institui o Sistema Nacional de Unidade de Conservação.

BRASIL. Ministério do Turismo. Ecoturismo: orientações básicas. Ministério do Turismo, Secretaria Nacional de Políticas de Turismo, Departamento de Estruturação, Articulação e Ordenamento Turístico, Coordenação Geral de Segmentação. 2. ed. - Brasília: 2010.

BRASIL. Lei federal no 12.651, de 25 de maio de 2012. Diário Oficial da República Federativa do Brasil, Poder Legislativo, Brasília, DF, 28 maio 2012. Seção 1, p.1.

CABRAL, A. V. Análise multicritério em Sistema de Informação Geográfica para localização de aterros sanitários. O caso da região sul da Ilha de Santiago, Cabo Verde. 2012. 100f. Dissertação (Mestrado em Gestão do Território com especialização em Detecção Remota e Sistemas de Informação Geográfica) - Faculdade de Ciências Sociais e Humanas - Universidade Nova de Lisboa, Lisboa, 2012.

CAIXETA, P. R. C.; PIMENTA, D. F. N.; AMARAL, R. V.; SCHAEFER, C. E. Análise multicritério (MCE) aplicada ao mapeamento de áreas susceptíveis a movimentos de massas na área urbana de Viçosa-MG. In: SIMPÓSIO BRASILEIRO DE CIÊNCIAS GEODÉSICAS E TECNOLOGIAS DA GEOINFORMAÇÃO, 9, 2012, Recife.

Anais...Recife: 2012. p.1-9.

CALIJURI, M. L.; MELO, A. L. O.; LORENTZ, J. F. Identificação de áreas para implantação de aterros sanitários com uso de análise estratégica de decisão. Revista de Informática Pública, v.4, n.2, p.23-250, 2002.

CARVALHO, J. R. M.; CURI, W. F.; CURI, R. C.; CARVALHO, E. K. M. A. Metodologia para avaliar a sustentabilidade ambiental de municípios utilizando análise multicritério. Revista 
REUNIR: Revista de Administração, Contabilidade e Sustentabilidade, v.1, n.1, p.18-34, 2011.

DOUROJEANNI, M. Planos de manejo I. Eco, Rio de Janeiro: 2005. Disponível em: <http:// www.oeco.org.br/marc-dourojeanni/16369oeco_13756 >. Acesso em: 14 mar. 2014.

EASTMAN, R.; JIN, W.; KYEM, P. A. K.; TOLEDANO, J. Rasters procedures for Multicriteria/ multi-objective decisions.

Photogrammetric Engineering and Remote Sensing, v.61, n.5, p.539-547, 1995.

FRANCO, R. A. M.; HERNANDEZ, F. B. T.; MORAES, J. F. L. O uso da análise multicritério para a definição de áreas prioritárias a restauração de Área de Preservação Permanente (APP), no noroeste paulista. In: SIMPÓSIO BRASILEIRO DE SENSORIAMENTO REMOTO. 16., 2013, Foz do Iguaçu. Anais...Foz do Iguaçu: 2013. p.3366-3373.

\section{SISTEMA INTEGRADO DE BASES} GEOESPACIAIS DO ESTADO DO ESPÍRITO SANTO - GEOBASES. 2002. INCAPER. Disponível em: http://www.geobases.es.gov.br/portal/. Acesso em: 03 ago. 2013.

\section{FUNDAÇÃO INSTITUTO BRASILEIRO DE} GEOGRAFIA E ESTATÍSTICA - IBGE. Mapa de vegetação do Brasil. Rio de Janeiro: 1993. 1p.

\section{INSTITUTO DE DEFESAAGROPECUÁRIA E FLORESTAL DO ES - IDAF. Plano de manejo do Parque Estadual Cachoeira da Fumaça. Versão resumida. Vitória: 2001. 42p.}

INSTITUTO ESTATUAL DE MEIO AMBIENTE E RECURSOS HÍDRICOS - IEMA. Ortofoto Mosaico cedido pelo IEMA. Vitória: 2007. 06 Ortofotos.

\section{INSTITUTO ESTATUAL DE MEIO AMBIENTE E} RECURSOS HÍDRICOS - IEMA. Parque

Estadual Cachoeira da Fumaça. Vitória: 2014. Disponível em: <http://

www.meioambiente.es.gov.br/ default.asp?pagina $=16700>$. Acesso em: 20 jun. 2014.
KÖEPPEN, W. Climatologia: con um estúdio de los climas de la Tierra. México: Fondo de Cultura Economica, 1948. 478p.

MARTINS, S. V. Recuperação de áreas degradadas: ações em áreas de preservação permanente, voçorocas, taludes rodoviários e de mineração. 3.ed. Viçosa, MG: Aprenda Fácil, 2013. v.1. 264p.

MEDEIROS, R.; PEREIRA, G. S. Evolução e implementação dos planos de manejo em Parques Nacionais no estado do Rio de Janeiro. Revista Árvore, v.35, n.2, p.279-288, 2011.

MORAES, W. V.; RIBEIRO, G. A.; LIMA, G. S.; GONÇALVES, W. Zoneamento do distrito de Rancharia, município de Lima Duarte, MG, entorno do Parque Estadual da Serra do Ibitipoca, com fins de manejo do ecoturismo. Revista Árvore, v.32, n.4, p.751-758, 2008.

OLIVEIRA, F. T.; SILVA, I. C.; MATOS, J. F. R.; HARA, F. A. S. Ecoturismo no Rio Puraquequara: suporte para inclusão social e proteção ambiental. Sociedade \& Natureza, v.22, n.2, p.283-295, 2010.

REZAEI, J.; ORTT, R. Multi-criteria supplier segmentation using a fuzzy preference relations based AHP. European Journal of Operational Research, v.225, n.1, p.75-84, 2013.

ROQUE, N.; LIDÓNIO, E.; FERNANDEZ, P.; ANJOS, O. Utilização de análise multicritério para avaliação do potencial apícola. In: ENCONTRO DE SISTEMAS DE INFORMAÇÃO GEOGRÁFICA, 4., 2013, Castelo Branco. - Aplicações SIG em Recursos Agro-Florestais e Ambientais: livro de resumos. Castelo Branco: IPCB, 2013. p.84-85.

SANCHES, J. Parque Estadual da Cachoeira da Fumaça. Revista ES Brasil, v.2, n.82, p.39-41, 2012.

TURBAY, C. V. G.; SILVA, R. C.; CARVALHO, T. R. R.; MUNARO, E. R. Cartografia geológica preliminar e petrologia no Parque Estadual da Cachoeira da Fumaça, ES - subsídios para gestão de unidade de conservação. Revista Geografares, n.10, p.176-202, 2012.

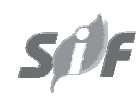


ZAMBON, K. L.; CARNEIRO, A. A. F. M.; SILVA, A. N. R.; NEGRI, J. C. Análise de Decisão Multicritério na Localização de
Usinas Termoelétricas Utilizando SIG.

Pesquisa Operacional, v. 25, n. 2, p.183199, 2005. 